STRUCTURAL BIOLOGY

ISSN 2059-7983

\title{
Structural biology of coronavirus ion channels
}

\author{
Francisco J. Barrantes*
}

Biomedical Research Institute (BIOMED), Catholic University of Argentina (UCA) - National Scientific and Technical Research Council (CONICET), C1107AFF Buenos Aires, Argentina. *Correspondence e-mail:

francisco_barrantes@uca.edu.ar

Received 27 November 2020

Accepted 8 February 2021

Edited by C. S. Bond, University of Western Australia, Crawley, Australia

Keywords: coronaviruses; COVID-19; SARS-CoV-2; cryo-electron microscopy; viroporins; structure-function correlations; viral ion channels.

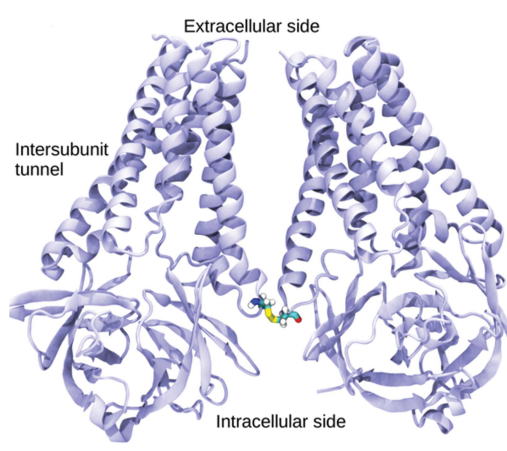

Viral infection compromises specific organelles of the cell and readdresses its functional resources to satisfy the needs of the invading body. Around $70 \%$ of the coronavirus positive-sense single-stranded RNA encodes proteins involved in replication, and these viruses essentially take over the biosynthetic and transport mechanisms to ensure the efficient replication of their genome and trafficking of their virions. Some coronaviruses encode genes for ion-channel proteins - the envelope protein E (orf4a), orf3a and orf8 - which they successfully employ to take control of the endoplasmic reticulum-Golgi complex intermediate compartment or ERGIC. The E protein, which is one of the four structural proteins of SARS-CoV-2 and other coronaviruses, assembles its transmembrane protomers into homopentameric channels with mild cationic selectivity. Orf3a forms homodimers and homotetramers. Both carry a PDZ-binding domain, lending them the versatility to interact with more than 400 target proteins in infected host cells. Orf8 is a very short 29 -amino-acid single-passage transmembrane peptide that forms cation-selective channels when assembled in lipid bilayers. This review addresses the contribution of biophysical and structural biology approaches that unravel different facets of coronavirus ion channels, their effects on the cellular machinery of infected cells and some structure-functional correlations with ion channels of higher organisms.

\section{Introduction and background}

Only a few weeks after the outbreak of the coronavirus disease 2019 (COVID-19) pandemic, biophysical studies produced atomic scale data on key structures of the causative agent, Severe acute respiratory syndrome coronavirus 2 (SARS-CoV-2). This attests to a very positive reaction by the scientific community in tackling a biomedical problem of unprecedented proportions. Structural biology was the first scientific discipline to apply powerful biophysical methods and produce solid data in attempts to understand the pathogenesis of the disease and search for its biomedical remediation (Barrantes, 2021).

From a genomic perspective, SARS-CoV-2 belongs to the same category of positive-strand RNA [(+)RNA] viruses as hepatitis $\mathrm{C}$, Chikingunya and Zika viruses. From a taxonomic viewpoint, SARS-CoV-2 belongs to the subfamily Coronavirinae in the Coronaviridae family that comprises four genera: Alphacoronavirus, Betacoronavirus, Gammacoronavirus and Deltacoronavirus (González et al., 2003; Letko et al., 2018). Coronaviruses (CoVs) pack between 26 and 32 kilobases of single-stranded positive-sense RNA inside their envelope. CoVs were first identified in the late 1970s in electron microscopy (EM) studies of negatively stained 
specimens and their name was coined due to the fuzzy solar corona appearance surrounding the spherical virion envelope (Almeida \& Tyrrell, 1967), which we now know stems from the coverage of the envelope with copies of the spike (S) protein, one of the four structural proteins in these viruses. The highly pathogenic avian bronchitis virus was discovered in the early 1930s (Estola, 1970), but it was not known until decades later that it belonged to the Gammacoronavirus genus of the Coronaviridae (González et al., 2003). CoVs cause mild to severe respiratory, enteric and neurological diseases in species ranging from avians to mammals (Lai \& Cavanagh, 1997; Cui et al., 2019; Woo et al., 2014).

The first study to identify a CoV infection in humans is attributed to Hartley and coworkers, who found antibodies to Mouse hepatitis virus (MHV) in the serum of affected patients (Hartley et al., 1964). A total of seven human CoVs (HCoVs) have since been identified. HCoV-OC43, HCoV-293, HCoVNL63 and HKU1-CoV generally cause mild respiratory diseases, mainly forms of the common cold, along with other viruses with tropism for the nasal and upper respiratory tract mucosae. A second category of HCoVs comprises the highly pathogenic SARS-CoV and MERS-CoV, the etiological agents of severe acute respiratory syndrome (SARS) and Middle East respiratory syndrome (MERS), responsible for the epidemics in 2003 and 2012, respectively, and SARS-CoV-2, the causative agent of the current COVID-19 pandemic.

The structural-functional correlations of SARS-CoV-2 ionchannel proteins and their comparison with those of other pathogenic CoVs have still not been fully characterized. This is an area that needs investigation, particularly because these proteins are purported to fulfil a role in infected cells, with possible implications for interventions that interfere with viral replication. This short review discusses the topic of ionchannel-forming protein structures in CoVs in general and in SARS-CoV-2 in particular, in an attempt to put the subject in perspective both from molecular biology and phylogenetic standpoints, and to draw attention to their potential as targets for prophylactic and/or therapeutic interventions.

Comprehensive reviews of the biological and evolutionary (Li et al., 2020), epidemiological (Su et al., 2016), clinical (Richardson et al., 2020; Guan et al., 2020), microbiological (Fung \& Liu, 2019) and physicochemical (Scheller et al., 2020) aspects and structure (Harrison, 2015; Tortorici \& Veesler, 2019) of CoVs have appeared. The reader is also referred to the reviews on the recent contribution of biophysics and structural biology to current advances in COVID-19 (Barrantes, 2021) and the new possibilities for repurposed drugs (Barrantes, 2020; Cavasotto \& Di Filippo, 2021; Cavasotto et al., 2021) in handling the current pandemic.

\section{Overall structure of CoVs}

A common characteristic of members of the Coronaviridae is the spiky appearance of the capsid (Neuman et al., 2006; Neuman \& Buchmeier, 2016; Wrapp et al., 2020). Contemporary cryo-EM images of the SARS-CoV-2 virion isolated from the supernatant of infected cells show roughly spherical bodies with a diameter of $91 \pm 11 \mathrm{~nm}$ (Ke et al., 2020), i.e. very similar to other CoVs. Around $70 \%$ of the SARS-CoV-2 genome encodes proteins involved in RNA replication, with the rest of the genome coding for structural and nonstructural proteins. Besides the aforementioned S protein, CoVs have three additional structural proteins, the nucleocapsid $(\mathrm{N})$, envelope (E) and membrane (M) proteins, 16 nonstructural proteins and eight open reading frame (ORF) accessory proteins (Díaz, 2020).

$\mathrm{N}$, the nucleocapsid protein, resides together with the RNA genome in the ribonucleoprotein (RNP) core inside the envelope. The $\mathrm{N}$ protein chaperones and protects the genomic RNA. The M protein is an integral membrane glycoprotein that contributes to adapting a region of the endoplasmic reticulum-Golgi complex intermediate compartment (ERGIC) membrane for virus assembly, thus defining the shape of the viral envelope. When expressed alone, $\mathrm{M}$ accumulates in the Golgi complex, but when expressed together with the E protein, virus-like particles that are akin to authentic virions in size and shape are assembled. This observation has led to the idea that the $\mathrm{M}$ and $\mathrm{E}$ proteins constitute the minimal building blocks for envelope formation (de Haan et al., 1999).

\section{Viral ion-channel-forming proteins (viroporins)}

In recent years, X-ray crystallography, transmission EM and cryo-EM and nuclear magnetic resonance (NMR) techniques have been applied to study the structures of some viral ionchannel-forming proteins, also termed 'viroporins' (Liao et al., 2006; Fischer \& Hsu, 2011). The name, partly borrowed from the bacterial $\beta$-barrel porins, alludes to their ability to act as ion-conducting pores in membrane bilayers, but in fact they are more elaborate than this, exhibiting, for example, ion selectivity. In silico studies using sequence-based molecular modelling and homology modelling have provided complementary insights into these structures, finding common architectures as well as diversity (see, for example, the review by OuYang \& Chou, 2014). Viroporins exhibit a low degree of homology with ion channels of prokaryotic or eukaryotic origin if one considers their overall structure, although their transmembrane (TM) regions do bear some resemblance to the corresponding regions of ion channels of higher organisms (Fischer \& Hsu, 2011), as analysed in the section on the evolution of these proteins.

One of the first descriptions of ion-channel proteins in viruses dates back to the early 1990s, when the matrix M2 protein of influenza virus was shown to confer ion permeability on monovalent cations upon heterologous transfection of Xenopus oocytes (Pinto et al., 1992). Subsequently, it was demonstrated that this applies to influenza A and B viruses, which also display permeability for protons, whereas the M2 proteins of influenza $\mathrm{C}$ and $\mathrm{D}$ viruses exhibit selectivity for chloride ions, with some permeability for protons (see the review by To \& Torres, 2019).

Between the genes coding for the $\mathrm{S}$ protein and those for other viral envelope genes, the CoV RNA genome contains a locus that is conserved throughout the entire family. In the 
SARS-CoV genome, this region includes a complete or truncated ORF (Zhang et al., 2014) containing the gene encoding the $\mathrm{E}$ protein (also termed orf4a), orf3a and orf8a, three proteins that form ion channels (Castaño-Rodriguez et al., 2018). The CoVs MERS-CoV, HCoV-229E, HCoV-OC43 and Porcine epidemic diarrhoea virus (PEDV) encode two such ion channel-forming proteins (To et al., 2016; CastañoRodriguez et al., 2018).

\section{The small E protein (orf4a): pentameric structure and membrane topology}

At only 76-109 amino acids long, $\mathrm{E}$ is the smallest of the four structural proteins of CoVs (Pervushin et al., 2009). It is an integral membrane protein that is present in substoichiometric quantities relative to other proteins embedded in the envelope bilayer membrane; its precise functions are still not fully known, except that its TM domain possesses ion-channel properties and is probably involved in virion assembly (Siu et al., 2008) and virion release from infected cells (reviewed in Schoeman \& Fielding, 2019). This has been documented for MHV; its expression in Escherichia coli leads to increased permeability, growth arrest and ultimately cell lysis (Madan et al., 2005). The genomes of SARS-CoV (Liao et al., 2013), MERS-CoV (Surya et al., 2015) and Infectious bronchitis virus (IBV), a highly pathogenic avian infectious bronchitis virus from the Gammacoronavirus genus (To et al., 2017), also code for E proteins. E possesses a short hydrophilic amino-terminal domain that is exposed to the cytoplasmic compartment of the host cell (Maeda et al., 2001; Raamsman et al., 2000) and a relatively long (25-amino-acid) TM domain. The TM domain of the E protein is highly conserved among CoVs, with $\sim 91 \%$ sequence identity and $98 \%$ sequence similarity (Cao et al., 2020).

The exact topology of E relative to the membrane is still an ongoing debate. Two amino acids are the main contributors to the hydrophobicity of the TM domain: valine and leucine ( $\mathrm{Wu}$ et al., 2003). The TM domain is followed by a long hydrophilic carboxy-terminus (Ye \& Hogue, 2007) containing three cysteine residues that have been suggested to play a role in the association of $\mathrm{E}$ with the spike glycoprotein $\mathrm{S}$ (Wu et al., 2003). Expression of the SARS-CoV E protein in Vero E6 cells showed that it is $\mathrm{N}$-glycosylated and that the two membranespanning domains comprise amino-acid sequences $11-33$ and $37-59$, i.e. with a short loop between the two (Chen et al., 2009). When analysing the TM region of $\mathrm{E}$, one should consider the two possible loci inhabited by this protein: (i) its native viral envelope bilayer lipid membrane and (ii) the hostcell intracellular membranes. In the former case, the E protein has been proposed to traverse the viral lipid bilayer as a single-passage helix (Raamsman et al., 2000) or a doublepassage helix (Raamsman et al., 2000; Maeda et al., 2001; Chen et al., 2009). During the life cycle in the host cell, E is mainly localized at the sites of viral replication, i.e. ER, Golgi and ERGIC membranes. Recombinant CoVs lacking the E protein show significantly lower viral titres/propagation-incompetent progeny, suggesting the importance of $\mathrm{E}$ in virion production and maturation (Schoeman \& Fielding, 2019). E from IBV has been reported to cross the Golgi membranes just once, with the N-terminus facing the Golgi lumen and the C-terminus facing the cytoplasm (Corse \& Machamer, 2000), whereas E from MHV is purported to traverse the lipid bilayer twice, with both the $\mathrm{N}$ - and $\mathrm{C}$-termini exposed to the cytoplasmic compartment, which is topologically equivalent to the interior of the virion (Maeda et al., 2001). A further proposal suggests that the TM region of SARS-CoV E contains a 12-amino-acid hairpin, which the authors propose is capable of deforming lipid bilayers by increasing their curvature, a process that would occur during virion budding from infected cells (Arbely et al., 2004). The NMR data of Torres and coworkers ( $\mathrm{Li}$ et al., 2014) appeared to confirm the suggestion of a hairpin-like structure formed by two helices joined by a less ordered segment in the SARS-CoV E monomer. Subsequent work from the same group indicated that $\mathrm{E}$ monomers possess only one membrane-embedded $\alpha$-helical segment.

In terms of their oligomeric organization, a molecularmodelling exercise led Torres and coworkers to suggest that the TM segments of SARS-CoV E protein monomers adopt a pentameric structure (Torres et al., 2005). NMR later led to experimentally supported models of the SARS-CoV E protein structure (Pervushin et al., 2009; Surya et al., 2018; Li et al., 2014).

Fig. 1(a) shows a model of the SARS-CoV E protein monomer obtained by solid-state NMR spectroscopy in detergent-lipid micelles. The recombinant $\mathrm{E}$ protein was expressed in bacteria and the lowest-energy structure was calculated (Li et al., 2014). A long straight $\alpha$-helix, the purported channel-forming domain, is joined through a flexible linker domain (residues 46-54) to a short peripheral C-terminal helix (residues 55-65) that bends obliquely with respect to the longer helix and to the main axis of the ionchannel pore (see Fig. 2) at the level of residue Tyr42. Subsequent NMR studies in lauryl-myristoyl-phosphatidyl glycerol (LMPG) micelles showed the monomer (residues 8-65) to consist of three segments, with the two $\alpha$-helices penetrating the bilayer and an overall shape resembling a fishing hook (Fig. 1b).

The homo-oligomer of the E protein is apparently selfgenerated through specific amino-acid linear motifs of five copies of the monomer, as suggested for the human coronavirus HCoV-OC43 (Stodola et al., 2018). Fig. 2 draws a comparison between the $\mathrm{E}$ proteins of the two related viruses SARS-CoV and SARS-CoV-2. The model of the SARS-CoV protein is derived from the NMR study in LMPG micelles (Surya et al., 2018) and that of the SARS-CoV-2 E structure is derived from NMR data at $2.4 \AA$ resolution of the protein reconstituted in ERGIC-mimetic liposomes containing phosphocholine, phosphoethanolamine, phosphatidylinositol, phosphoserine and cholesterol (Mandala et al., 2020). For comparative purposes, liposomes made up of dimyristoylphosphocholine (DMPC):dimyristoylphosphoglycerol (DMPG) membranes were employed. The NMR structures depart from an ideal $\alpha$-helical geometry, apparently due to deformations produced by three phenylalanine residues stacked between 
the helical chains lining the narrow pore. The blocker hexamethylene amiloride binds to polar amino-acid residues in the amino-terminal lumen of the pore.

The ring of TM segments forming the SARS-CoV-2 protein $\mathrm{E}$ ion channel proper is also a pentameric bundle, but the helices run perpendicular to the membrane plane, whereas in the SARS-CoV E protein the homologous chains of the five monomers are assembled into a pentameric body with an inner ring of TM $\alpha$-helical segments (residues 15-45) tilted by $\sim 15^{\circ}$ relative to the axis of the central ion-permeation pathway (Fig. 2, top panel). The most striking difference between the SARS-CoV and SARS-CoV-2 ion channels is the simpler architecture of the latter, with a bundle of straight $\alpha$-helical chains forming a single ring, contrasting with the two helical rings in SARS-CoV. Since the two proteins share $\sim 92 \%$ sequence homology, the possibility arises that the different structures of their membrane-associated regions are partly due to the different media used in the NMR studies. A pentameric structure has also been proposed for the E protein of MERS-CoV (Surya et al., 2018).

In functional terms, early studies using planar lipid bilayers showed that synthetic peptides corresponding to the SARS$\mathrm{CoV} \mathrm{E}$ protein form ion channels in planar lipid bilayers with selectivity for permeating monovalent cations over monovalent anions (Wilson et al., 2004). The E protein of SARS$\mathrm{CoV}$ was also found to modify the permeability of $E$. coli membranes when expressed under reducing conditions, under

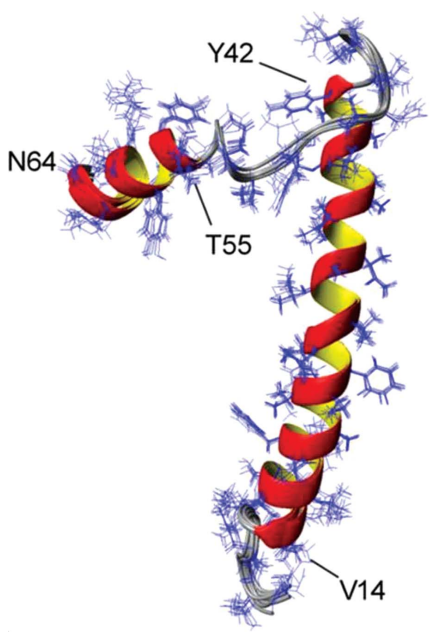

(a)

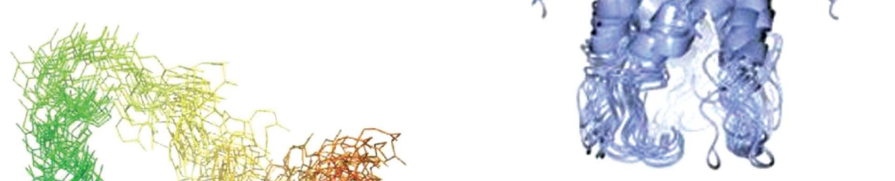

(a)

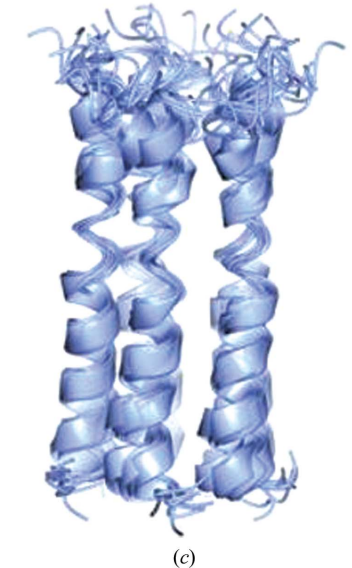

(c)

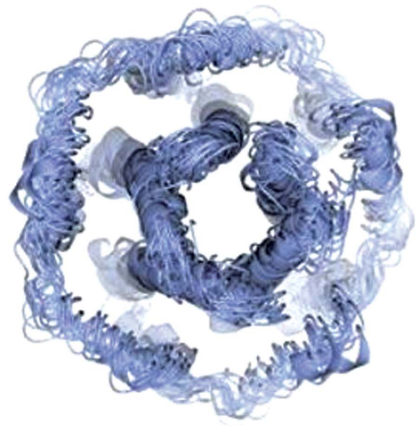

(b)

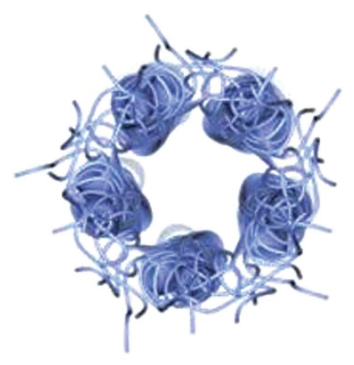

(d)
NMR work by the Torres group led to early models of the monomeric form of the SARS-CoV E protein in detergent-lipid micelles ( $\mathrm{Li}$ et al., 2014), showing two helical segments joined by a more disordered flexible region flanked by amino-acid residues Tyr42 and $\operatorname{Thr} 55(a)$. The $\mathrm{N}$ terminal portion of the TM region [indicated by residue Val14 in $(a)$ ] is purported to protrude into the lumenal side of the Golgi membranes, and the C-terminal portion (here indicated by Asn64) to be partly exposed to the cytoplasm. (b) Subsequent work showed the calculated E monomers to consist of three $\alpha$-helical segments in LMPG micelles. The model shown corresponds to an ensemble of ten calculated monomeric structures, with the backbone rendered as a line representation. Reproduced from Surya et al. (2018) with permission from Elsevier Masson SAS under the Creative Commons Attribution licence (https:// creativecommons.org/licenses/by/4.0).

which $\mathrm{E}$ adopts a monomeric state, whereas nonreducing conditions rendered the $\mathrm{E}$ protein in dimeric and homo(Liao et al., 2004). Reduction exposed two intial for $\mathrm{S}-\mathrm{S}$ bond-mediated oligomerto the exposure of the cysteine residues, although no dist tion could be established between the direct and indirect nature of the permeability changes using planar lipid bilayers (Verdiá-Báguena et al., 2012). The E channel displays monovalent cation selectivity (Westerbeck \& Machamer, 2019), although it has also been reported to permeate $\mathrm{Ca}^{2+}$ (NietoTorres et al., 2015). Ion conductance can be blocked by hexamethylene amiloride, but not by amiloride, a drug that s the viral replication of some synthetic E proteins from (Pervushin et al., 2009). Based on the conductance properties of E in planar bilayers (Wilson et al., 2004) or upon was suggested to form nonselective channels for monovalent cations, although in the latter case $\mathrm{Li}^{+}$partially reduced the inward currents (Zhang et al., 2014). As observed with orf3a,

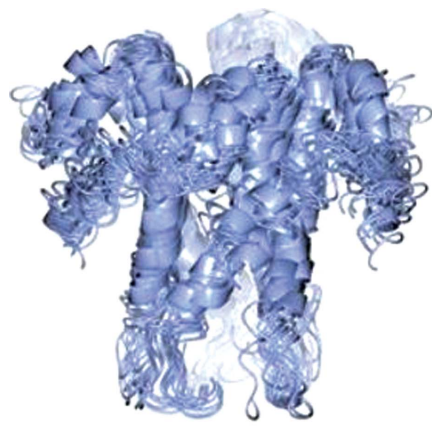

Figure 2

Comparative views of SARS-CoV and SARS-CoV-2 E protein models derived from NMR data. The top panel shows the lowest-energy NMRderived structural model of the SARS-CoV E protein homopentamer (PDB entry 5x29; Surya et al., 2018) in a lateral view (a) and an end-on view $(b)$. The bottom panel shows an NMR-derived model of the SARSCoV-2 E protein (PDB entry 7k3g; Mandala et al., 2020) in lateral (c) and end-on $(d)$ views. Notice that the ion-channel-lining helices of the SARS$\mathrm{CoV}$ E protein are more perpendicular to the membrane plane compared with those of the SARS-CoV E protein. Images were produced using CCP4mg (McNicholas et al., 2011). 
viral production diminished when protein $\mathrm{E}$ expression was abrogated by applying siRNA to infected cells (Zhang et al., 2014). The permeability properties of the new SARS-CoV-2 E protein reconstituted in lipid bilayers with a composition reported to mimic that of the ERGIC membrane has recently appeared, showing that the ion channel displays a mild cationic permeability. This can be blocked by the binding of hexamethylene amiloride and amantadine to polar residues shallowly located at the N-terminal lumen (Mandala et al., 2020), thus confirming earlier work on the inhibitory action of this drug on the viral channel (Pervushin et al., 2009).

In vitro experiments have shown that the lipid composition of the host planar bilayer modulates the ion conductance of the SARS-CoV E protein channel (Verdiá-Báguena et al., 2012). Lipid charge was also found to play a role: the E protein showed no cation selectivity in uncharged lipid membranes, whereas negatively charged lipids resulted in mild cationic selectivity (Verdiá-Báguena et al., 2012). The charge of the ionizable groups of the E protein, as well as those from host lipids such as diphytanoyl phosphatidylserine, was found to modify channel conductance (Verdiá-Báguena et al., 2013).

The mutagenesis of amino-acid residues in the hydrophobic $\mathrm{TM}$ domain of the $\mathrm{E}$ protein alters virus replication, which is restored upon re-establishing the $\alpha$-helical structure (Ye \& Hogue, 2007). Helix-restored $\mathrm{E}$ protein is more sensitive to treatment with hexamethylene amiloride, a drug that inhibits the HIV ion channel $\mathrm{Vpu}$ and the $\mathrm{E}$ protein channel from human HCoV-229 and rodent MHV, but not avian IBV (Wilson et al., 2006). N15A and V25F mutations in the TM region of the SARS-CoV $\mathrm{E}$ protein have been reported to abrogate ion conductance (Verdiá-Báguena et al., 2012).

\section{Orf3a}

SARS-CoV orf3a is a much larger (274 amino acids) viral ionchannel protein; it possesses three transmembrane domains. Initially described as a structural protein unique to SARSCoV (Shen et al., 2005), it was subsequently reported that the orf3a protein from the same virus, named U274 by these authors, was a nonstructural protein that interacted with the M, E and S structural proteins and orf7/U122 (Tan et al., 2004). Recombinant SARS-CoV orf3a protein can form a homotetrameric complex in orf3a-transfected cells (Lu et al., 2006; Marquez-Miranda et al., 2020). A tetramer consisting of four TM segments each has also been proposed using computational structure-prediction approaches (Wang et al., 2012). When expressed in Xenopus oocytes, SARS-CoV orf3a is a $\mathrm{K}^{+}$-sensitive channel that can efficiently be inhibited by $\mathrm{Ba}^{2+}$. Similarly, ion-channel activity is generated upon transfection of PEDV into Xenopus oocytes or yeast cells (Wang et al., 2012). If cells are transfected with siRNA, thus suppressing orf3a expression, infection with SARS-CoV replication is not affected, but virion release is (Lu et al., 2006). Synthetic peptides corresponding to each of the constituent TM segments of orf3a were reconstituted into artificial lipid bilayers. When the three peptides were assembled in a 1:1:1 mixture, ion-channel activity was observed, but either TM2 or
TM3 was required to induce currents; TM1 failed to do so. Full-length orf3a expression showed weak cationic selectivity and rectification (Chien et al., 2013).

Recently, SARS-CoV-2 orf3a was heterologously expressed in Spodoptera frugiperda, reconstituted in liposomes, and single-channel currents were recorded from excised patches (Kern et al., 2020). Electrophysiologically, orf3a behaved as a cation channel with a large single-channel conductance (375 pA) with modest selectivity for $\mathrm{Ca}^{2+}$ and $\mathrm{K}^{+}$over $\mathrm{Na}^{+}$. The channel was not blocked by $\mathrm{Ba}^{2+}$ as was the case for the SARS-CoV channel (Lu et al., 2006), nor was it inhibited by the small drug emodin.

Kern and coworkers also employed cryo-EM to image the apo form of the dimeric and tetrameric structures of orf3a reconstituted in lipid nanodiscs. SARS-CoV-2 appears as a homotetramer in which each monomer of the dimers contributes three TM segments arranged in clockwise fashion, making a total of six membrane-spanning domains per dimer (Figs. $3 a$ and $3 b$ ). Dimers are joined by a covalent $\mathrm{S}-\mathrm{S}$ bond distended between homologous Cys133 residues in each dimer in the in silico model produced by Marquez-Miranda et al. (2020) (Fig. 3b) or residues Trp131, Arg134, Lys136, His150, Thr151, Asn152, Cys153 and Asp155 in the recent molecularmodelling studies of Cavasotto and coworkers (Cavasotto \& Di Filippo, 2021; Cavasotto et al., 2021), bringing the total number of TM helices to 12 and thus making this the largest and most elaborate viral channel protein known to date. The $\sim 2.9 \AA$ resolution cryo-EM structure of SARS-CoV-2 orf3a (Kern et al., 2020) is very similar to that of the orf3a channel structure of SARS-CoV (Lu et al., 2006), corroborating the structural homology between several of the molecular constituents of these two human pathogenic viruses from the seven known to date. The all-helical TM region of the protein, with a length of $\sim 40 \AA$, adopts a peculiar novel topography in the lipid bilayer, whereas the cytosolic domain of the dimer $(\sim 30 \AA$ ) is formed by two $\beta$-sandwiches (Fig. $3 c$ ). The novel ion-channel structure possesses two potential ion pores, one in each dimer; the walls of the ion channel proper are lined by TM1 and TM2 of each monomer (Fig. 3c). The extracellularfacing end of the ion channel exhibits a narrow bifurcated pore that is reminiscent of the structure of vestibules in ion channels of higher organisms. This outer portion of the channel leads to a large polar cavity that is open to the cytosol. The orf3a structure was captured by cryo-EM in a conformation tentatively corresponding to a tetramer, and ascribed by the authors to the closed or inactivated state (Kern et al., 2020). A tubular electron-dense region potentially corresponding to lipid acyl chains was partially resolved in between the TM helices.

Interestingly, the molecular model from the cryo-EM data of the orf 3a protein (PDB entry 6xdc; Marquez-Miranda et al., 2020) disclosed the presence of chloride-binding sites inside the ion-permeation pathway of SARS-CoV-2 orf3a.

\section{Orf8a}

Information on Orf8a is still very scanty. It is a cysteine-rich 29-amino-acid single-passage TM peptide present at least in 
SARS-CoV. Orf8a forms cation-selective ion channels with a conductance close to $9 \mathrm{pS}$ when assembled in lipid bilayers in several putative oligomeric forms from tetramers to hexamers (Chen et al., 2011). In silico calculations suggested that the first

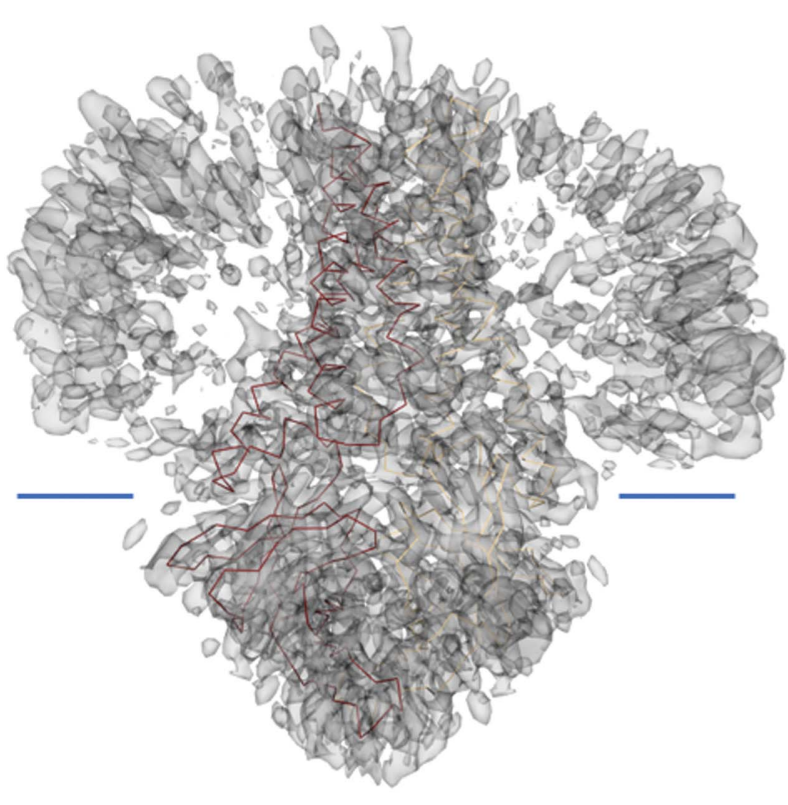

(a)

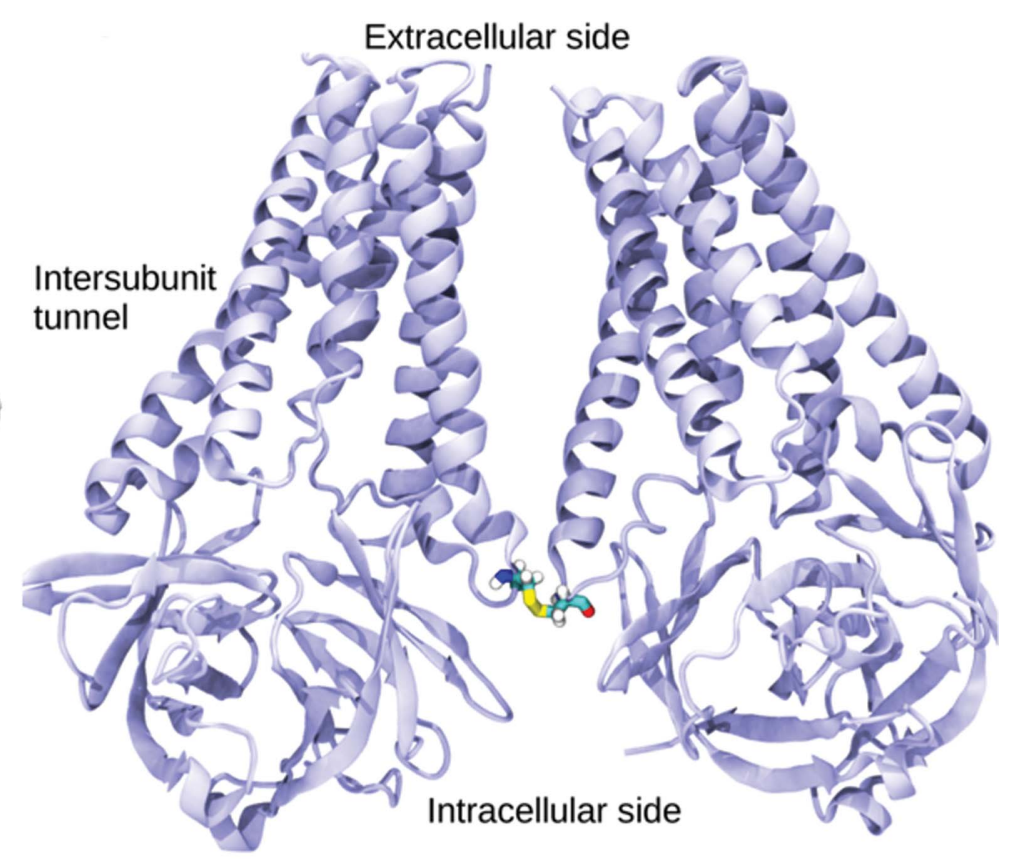

(b)
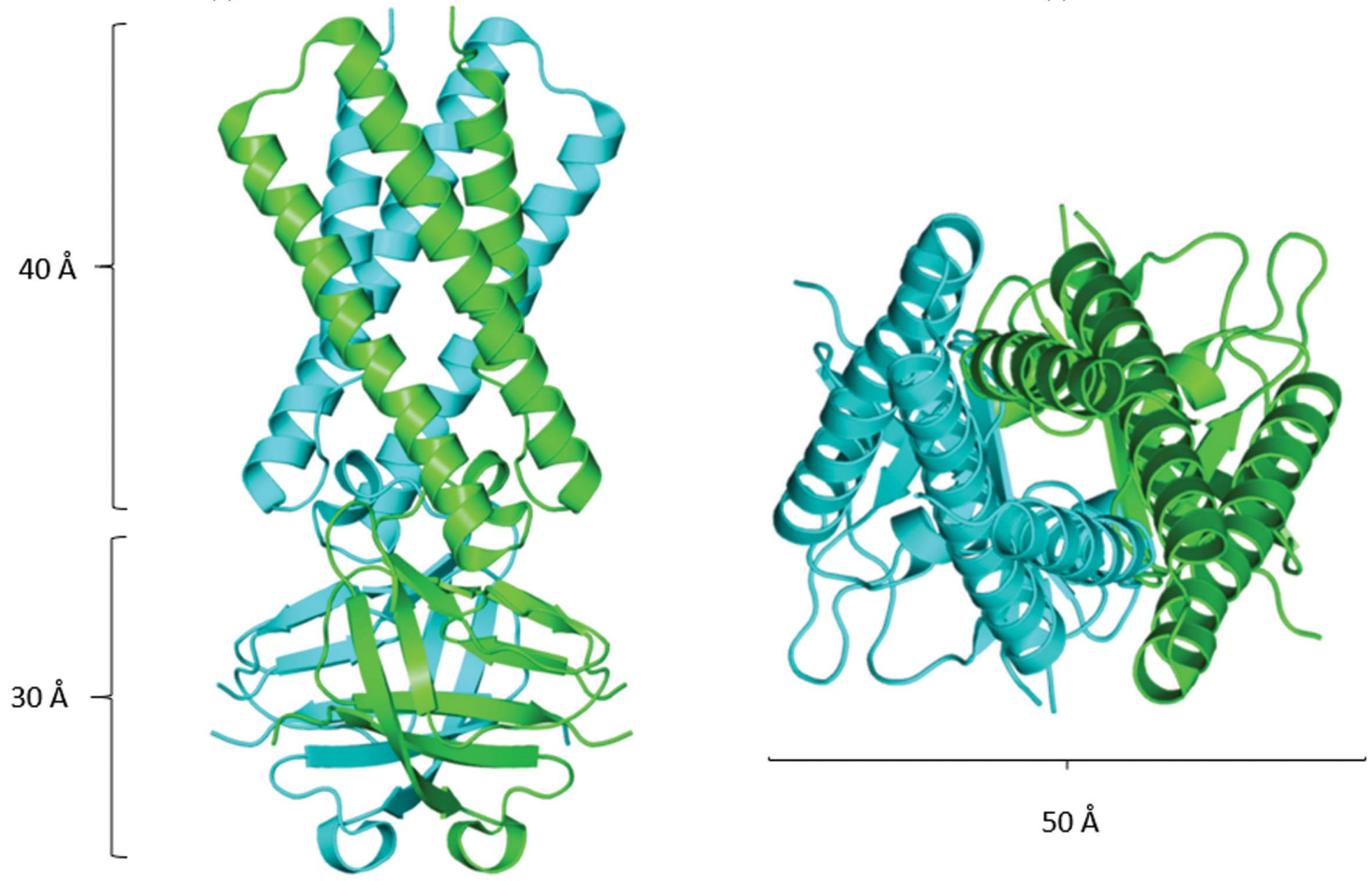

$(c)$

Figure 3

(a) Cryo-EM map at $2.9 \AA$ resolution of the full-length SARS-CoV-2 orf3a tetramer expressed in S. frugiperda and reconstituted in lipid nanodiscs (Kern et al., 2020; EMDB entry EMD-22136). The backbone chain of one of the protomers docked into the cryo-EM map is outlined in burgundy. The horizontal blue lines mark the limit between the upper TM domain and the lower cytoplasmic domain of the tetramer formed by multiple $\beta$-sheets. $(b)$ Ribbon model of the SARS-CoV-2 orf3a tetramer derived from cryo-EM studies of the protein reconstituted in lipid nanodiscs. Each dimer possesses six TM helices and a cytoplasmic domain with predominantly $\beta$ secondary structure. The two dimers in the tetramer are purported to be covalently joined by a disulfide bond formed by homologous Cys133 residues in each monomer (Marquez-Miranda et al., 2020). The molecular-modelling study by these authors revealed the presence of a chloride ion site in the channel lumen. (c) Ribbon models of the SARS-CoV- 2 orf3a dimer: an $\sim 70 \AA$ cylinder in a lateral view (left) and an end-on perspective as viewed from the extracellular side (right) derived from cryo-EM studies of the protein reconstituted in lipid nanodiscs (Kern et al., 2020). Each protomer of the dimer has three helices that can fully traverse a lipid bilayer ( $\sim 40 \AA$ ) and a $30 \AA$-long cytoplasmic domain with predominantly $\beta$ secondary structure. The projection of the dimer onto the membrane plane is elliptic, with a major axis of $\sim 50 \AA$ in width. The central ion path is flanked by TM segments 1 and 2 , as seen in the centre of the end-on view. Images were produced using $C C P 4 m g$. 
22 amino acids of the single-TM domain of orf8a form a homopentameric bundle (Hsu et al., 2015). The pentameric bundle was also purported to exhibit weak cation selectivity attributable to hydrophilic and hydrophobic stretches of amino acids in the channel lumen.

\section{The contribution of viral ion-channel proteins to pathogenesis}

SARS-CoV orf3a has been implicated in viral release, inflammasome activation and cell death, and its deletion reduces viral titres and morbidity in model systems (Freundt et al., 2010). E downregulates the type-1 interferon (IFN) receptor by inducing serine phosphorylation of the IFN $\alpha$-receptor subunit 1 degradation motif and increasing receptor ubiquitination (Minakshi et al., 2009).

The fact that a large proportion $(>70 \%)$ of the $\mathrm{CoV}$ genome, including that of SARS-CoV-2, is devoted to RNA replication dictates the preferential intracellular tropism of the virus to the biosynthetic machinery of the cell. Viral proteins are initially synthesized in the endoplasmic reticulum (ER), but most of the post-translational modifications occur at the overlapping interface of the ER and the Golgi complex: the ERGIC zone. Indeed, labelling the E protein with Rab-1, a cytochemical marker of the intermediate compartment and the ER, showed the accumulation of MHV CoV-A59 E protein in the ERGIC region of the cell; electron microscopy provided further evidence that $\mathrm{E}$ induces the formation of tubular structures and induces curvature of the pre-Golgi membranes, subsequently altering the Golgi-complex membranes (Raamsman et al., 2000; Nieto-Torres et al., 2015). E is purported to confer stability to the viral membrane and to contribute to the later stages of the virion cycle in the infected cell: the assembly and budding processes (Neuman et al., 2011). E assembles by budding into the lumen of the early Golgi compartment (Westerbeck \& Machamer, 2019). Alanine-scanning mutagenesis studies of the extramembrane domain of $\mathrm{E}$ have shown that certain mutations impair viral assembly and maturation, i.e. morphogenesis of MHV virions (Fischer et al., 1998; Siu et al., 2008). Although according to some authors (Venkatagopalan et al., 2015) E does not traffic to the cell surface, avian IBV E protein interacts physically with the $\mathrm{M}$ protein and is able to retain $\mathrm{M}$ in the compartment that it resides in (Lim et al., 2001). In SARS-CoV this interaction is postulated to take place through the hydrophobic TM domains (Chen et al., 2009). Propagation and shedding of SARS-CoV virus-like particles requires the co-expression of $\mathrm{E}$ and $\mathrm{N}$ proteins together with the M protein (Siu et al., 2008).

In addition to these roles in the assembly, trafficking and shedding of virions, the $\mathrm{E}$ protein is also involved in the stimulation of the immune response in the infected organism. The evolutionary conservation of the $\mathrm{E}$ protein among CoVs (Cao et al., 2020) makes it an interesting candidate for vaccine development, and therefore knowledge of its surface epitopes is of biological and biotechnological importance. A step in this direction is the tentative mapping of the surface epitopes of the SARS-CoV-2 E protein based on the structure from
SARS-CoV (Tilocca et al., 2020; Fig. 4). Polyclonal antibodies that recognize the N-terminal 19 amino-acid residues of the SARS-CoV E protein inhibit its ion-current ability (Wilson et al., 2004).

Ion-channel activity resulting from the expression of $\mathrm{CoV}$ viroporins induces stress responses and activates proinflammatory pathways, and can lead to cell death (Minakshi et al., 2009). In vitro, expression of the SARS-CoV orf3a protein in the pulmonary epithelial cell line A549 upregulates the expression of intracellular and secreted levels of the three subunits of fibrinogen (Tan et al., 2005). Infection of Vero E6 cells with SARS-CoV leads to apoptosis, which in turn triggers a virus-initiated cytopathic effect (Yan et al., 2004). Other pathogenic changes include rearrangement of the membrane (accumulation of intracellular vesicles), Golgi fragmentation and cell death induced by SARS-CoV orf3a, which is reduced upon deletion of orf3a (Freundt et al., 2010). The virus also downregulates the inositol-requiring enzyme 1 (IRE-1) signalling pathway in the unfolded protein response (DeDiego et al., 2011). Most recently, the orf3a protein of SARS-CoV-2 has also been shown to induce apoptosis in various cell lines in vitro. The apoptotic process involves the activity of caspase- 8 , i.e. following the so-called extrinsic pathway, which induces the release of mitochondrial cytochrome $c$ and caspase-9 activation; the levels of apoptosis were, however, lower than those induced in Vero E6 cells by SARS-CoV (Ren et al., 2020).

Another expression of the pathogenic effects induced by the SARS-CoV E protein is the increase in permeability of the ERGIC/Golgi membrane, leading to the cytosolic release of $\mathrm{Ca}^{2+}$ with concomitant activation of the NLRP3 inflammasome and induction of interleukin $1 \beta$ (IL-1 $\beta$ ) production (Nieto-Torres et al., 2015). When (+)RNA viruses such as the CoVs utilize the host-cell ERGIC membranes to reproduce their genomes, they modify this membrane complex to produce a structurally different organelle: the replication complex or replication organelle (Snijder et al., 2020). This modified intermediate membrane compartment is characterized by the appearance of double-membrane vesicles (DMVs) $\sim 250-300 \mathrm{~nm}$ in diameter where the double-stranded RNA is copied into new (+)RNA genomes (Fig. 5). How is the nascent genomic (+)RNA released from inside the DMVs into the cytosol? A recent cryo-EM tomography study of cells infected with SARS-CoV-2 and other CoVs such as MHV identified a pore traversing the two adjacent lipid bilayers of the DMVs. The pore is formed by six copies of the nonstructural protein nsp3 essential for viral replication (Wolff et al., 2020).

Analogous structures called necked spherules can be observed in cells infected with other (+)RNA viruses such as Zika virus (a flavivirus), Chikungunya virus (an alphavirus) and nodaviruses. In the latter case, RNA-replication organelles were imaged by cryo-EM tomography in the outer mitochondrial membrane opening towards the cell cytoplasm. The spherule neck appears as a ring containing 12 copies of the nodavirus RNA-replication protein A (Unchwaniwala et al., 2020). 
CoV pathogenesis is intimately related to the ability of the infective viruses to hijack the various molecular effectors required to bind to and enter the host cell, replicate their RNA, assemble and be released from the host cell. Viral assembly and intracellular migration is tightly coupled to the
ERGIC cellular machinery and its vesicle-mediated transport. Expression of the E protein from avian IBV has recently been discovered to induce neutralization of the Golgi $\mathrm{pH}$, altering the secretory pathway through interaction with host-cell factors, thereby protecting the IBV spike protein $\mathrm{S}$ from premature cleavage and increasing the efficacy of infective virion release from

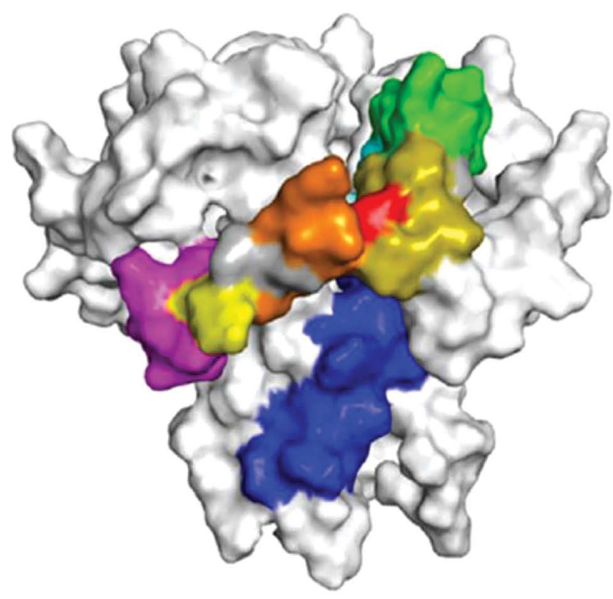

(a)

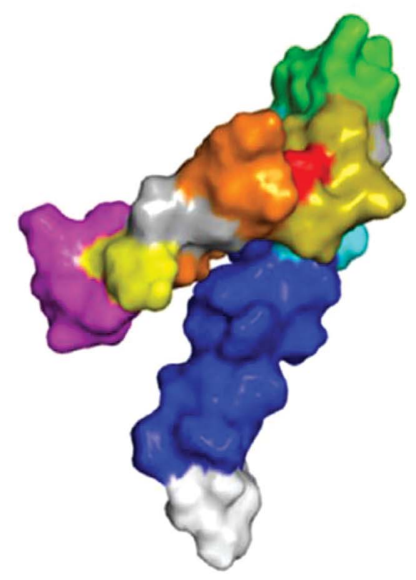

(b)
Figure 4

Putative surface epitopes of the SARS-CoV and SARS-CoV-2 E proteins. (a) Model of the homopentameric SARS-CoV E protein (PDB entry 5x29). Selected epitope sequences are mapped in each monomer as displayed in $(b)$. Epitope sequences are coloured as follows: blue, LIVNSVLLFLAFVVFLLVTLAILTALRLCAY; cyan, LLVTLAILTALRLCA; green, LTALRLCAY; olive green, CNIVNVSLVKPSFYV; red, SLVKPSFYV; orange, LVKPSFYVYSRVKNL; yellow, LVKPSFYVY; magenta, KPSFYVYSRVKNLNS. Reproduced from Figs. $2(a)$ and $2(b)$ of Tilocca et al. (2020) with permission from Elsevier Masson SAS under the Creative Commons Attribution licence (https://creativecommons.org/licenses/by/4.0). the cell (Westerbeck \& Machamer, 2019).

Successful expression of the E protein thus appears to be an essential requisite for pathogenesis; in fact, attenuated SARS-CoV virions lacking $\mathrm{E}$ proteins have been suggested as vaccine candidates (Netland et al., 2010). Viruses lacking both $\mathrm{E}$ and orf3a are not viable, and full-length $\mathrm{E}$ and orf3a proteins are required for maximal SARS-CoV replication and virulence. In contrast, the viroporin orf8a has only a minor impact on these activities (Castaño-Rodriguez et al., 2018).

E-protein-mediated channel activity has been correlated with enhanced pulmonary damage following accumulation of liquid and electrolytes in pulmonary oedema observed in SARS, driven by the inflammasome NLRP3 and IL- $1 \beta$ overexpression (Nieto-Torres

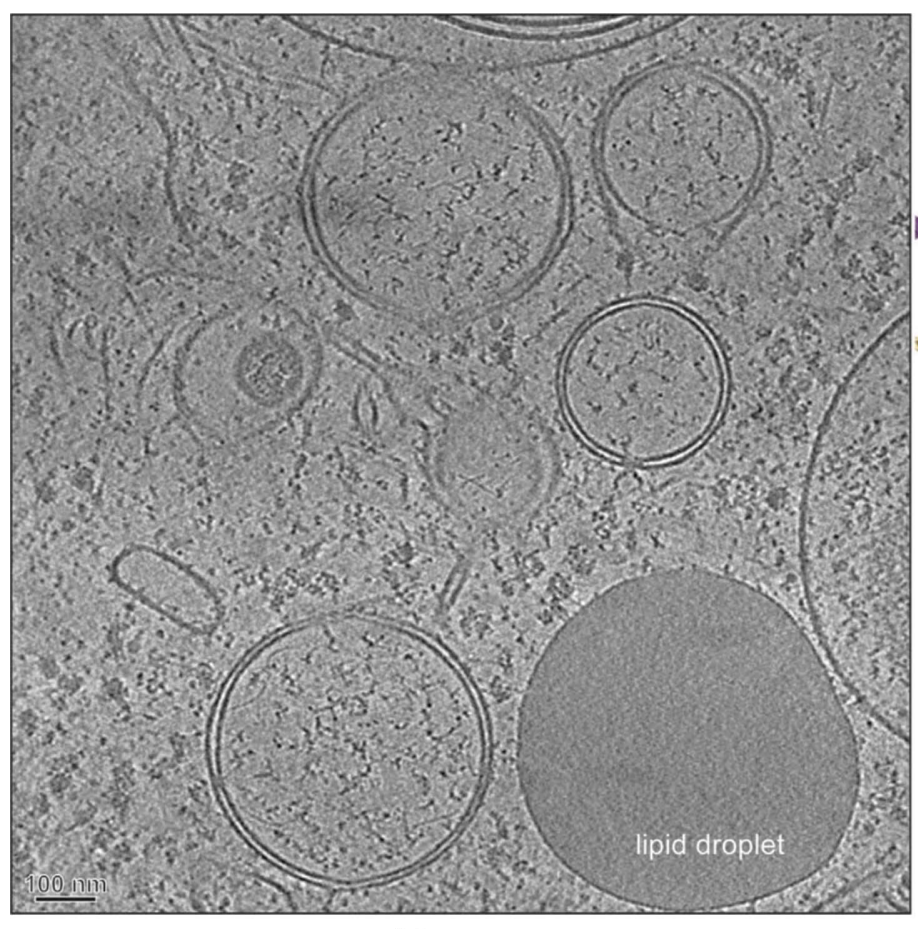

(a)

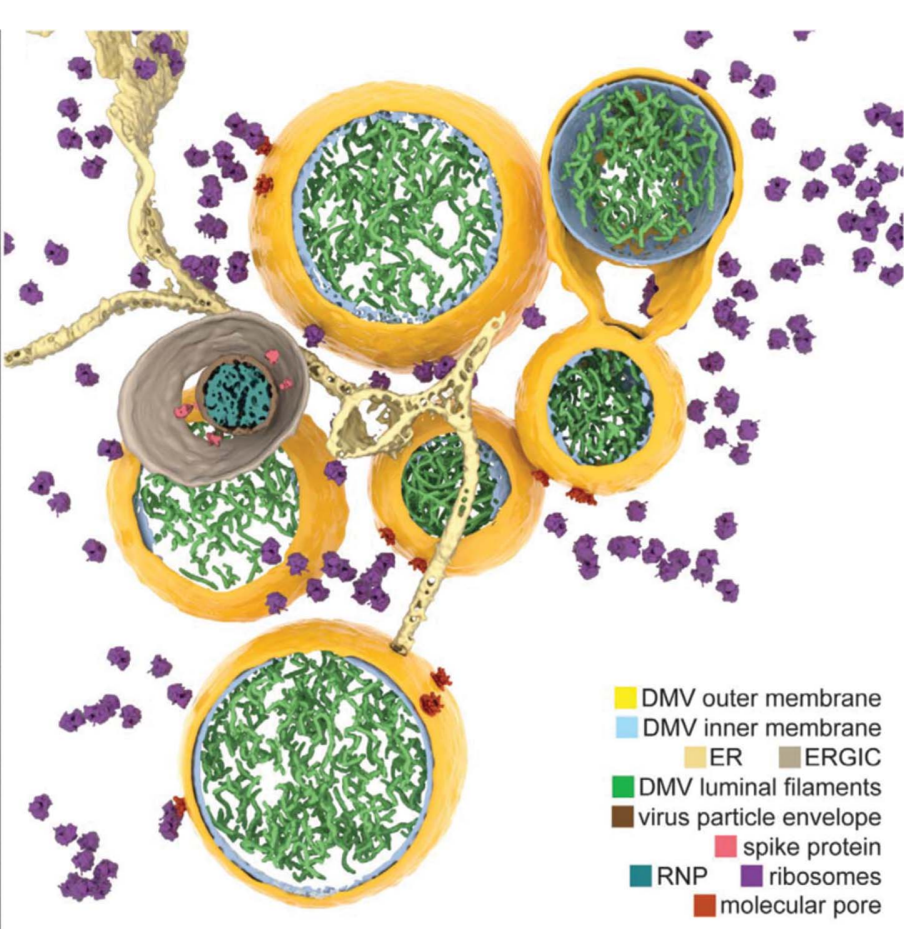

(b)

Figure 5

CoV-induced DMVs revealed by cryo-EM tomography. (a) Tomographic slice ( $7 \mathrm{~nm}$ thick) of a cryo-lamella milled through an MHV-infected cell at a middle stage of infection. (b) 3D model of the tomogram, with the segmented content annotated. ERGIC, ER-to-Golgi intermediate compartment. Reproduced from Fig. 1 of Wolff et al. (2020) with permission from the publisher under the Creative Commons Attribution licence (https:// creativecommons.org/licenses/by/4.0). 
et al., 2015). Porcine reproductive and respiratory syndrome virus infection also involves inflammasomes and IL- $1 \beta$ induced inflammation and injury (Zhang et al., 2013). This pathology could be related to disruption of the epithelial apicobasal integrity in alveolar cells. In fact, SARS-CoV E protein has been shown to interact with PALS1, a tightjunction-associated protein in mammalian cells (Teoh et al., 2010). The interaction is mediated by a PDZ-binding motif at the carboxy-terminus of $\mathrm{E}$ that binds to a PDZ domain in PALS1. The authors speculate that SARS-CoV E hijacks PALS1 through this mechanism, abrogating epithelial cell differentiation, a phenomenon that could also occur in the alveolar cells in the pulmonary affectation of SARS (Teoh $e t$ al., 2010) or SARS-CoV-2. In the case of MHV, expression of E results in cellular apoptosis (Maeda et al., 2001). The PDZbinding motif in $\mathrm{E}$, which is also present in the orf3a channelforming protein, lends it the capacity to bind to more than 400 target proteins in the infected host cells (Castaño-Rodriguez et al., 2018), thus giving these viroporins sufficient versatility to perturb multiple aspects of normal cell function.

The E protein is probably involved in the neurotropism of CoVs. The human $\mathrm{CoV} \mathrm{HCoV}-\mathrm{OC} 43$ requires full expression of its $\mathrm{E}$ protein for efficient replication and propagation in neuronal cells in culture and for neurovirulence in the central nervous system (Stodola et al., 2018).

\section{Therapeutic potential of channel blockers acting on} CoV ion channels

The COVID-19 pandemic has given new impetus to research on the E proteins of Betacoronavirus, the genus to which SARS-CoV-2 belongs. A genomic analysis of the entire database of betacoronaviruses showed that the gene coding for the $\mathrm{E}$ protein is segregated into three different clusters, one of which includes only SARS-CoV, SARS-CoV-2 and two bat CoVs. SARS-CoV-2 E and the two bat CoVs are $100 \%$ identical, whereas $\mathrm{E}$ from SARS-CoV and SARS-CoV-2 shows $95 \%$ homology (Alam et al., 2020). The five C-termini of the homopentamer protrude into the cytoplasmic compartment, where three point mutations (The55Ser, Val56Phe and Glu69Arg) and a deletion (Gly70) mark the difference between the latter two viruses. The extremes of the C-terminal regions also harbour the loci of the key tetrapeptide segment (DLLV) involved in PDZ-domain recognition (Alam et al., 2020).

The ion-channel function of the SARS-CoV-2 E protein has recently been explored experimentally in bacteria using three indirect assays of channel activity: growth deficiency upon overexpression, growth recovery in a $\mathrm{K}^{+}$uptake-deficient E. coli strain and cytoplasmic acidification in acidic growth media (Singh Tomar \& Arkin, 2020). Exploring a library of repurposed drugs, these authors find that glicazide, which is of therapeutic application in type-2 diabetes mellitus, apparently blocks channel activity, as does the drug memantine. Memantine is a low-affinity, voltage-dependent, noncompetitive antagonist of the glutamatergic NMDA receptor, the 5-HT3 receptor and the $\alpha 7$ nicotinic acetylcholine receptor, which are three members of the pentameric ligand-gated ion channels (pLGICs), and is also an agonist of the dopamine D2 receptor. Memantine is used as a drug in Alzheimer's disease, with its therapeutic ability apparently residing in its channelblocking activity. Using a prokaryotic model system, the proton- and GABA-gated pentameric ion-channel protein GLIC from the bacterium Gloeobacter violaceus, Ulens and coworkers showed that memantine blocks channel activity by obstructing the channel vestibule facing the extracellular milieu (Ulens et al., 2014).

The drug 5-( $N, N$-hexamethylene)amiloride has been shown to block the SARS-CoV E protein channel in a manner similar to the mechanism operating on the HIV-1 Vpu channel (Wilson et al., 2006). Other viroporins, albeit from non-CoV viruses, have also been found to be potential targets of blocking compounds that interfere with the assembly and release of mature virions (Behmard et al., 2018).

Second to the large superfamily of G-protein coupled receptors (GPCRs), ion channels are among the most soughtafter membrane-protein targets by the United States Federal Drug Administration. Ion-channel modulators in particular have shown therapeutic potential and successes, for example as blockers of influenza M2 channels (Moorthy et al., 2014; Sakai et al., 2018; Niu et al., 2019). It is expected that the current pandemic will prompt further research into this important area, with obvious therapeutic opportunities.

\section{Viral ion-channel proteins, lipid domains and evolution}

As analysed in the preceding section, several drugs with pharmacological activity as ion-channel blockers also inhibit ion fluxes mediated by viral ion-channel proteins. Here, I speculate on other possible common features between the two types of channels. It is estimated that about 4000 million years ago planet Earth witnessed the appearance of protein molecules with the capacity to selectively permeate ions through the plasma membranes of prokaryotic organisms such as the cyanobacterium $G$. violaceus or the bacillus Erwinia chrysanthemi. Comparison of the crystal structures of these proteins in prokaryotes and their homologs in eukaryotes has led to the notion that they belong to the same superfamily of pLGICs (Tasneem et al., 2004) that share a high degree of structural homology and phylogenetic conservation (Barrantes, 2015). Furthermore, scrutiny of the ion-channel protein phylogeny disclosed interesting points of contact with the evolution of the machineries involved in lipid and, in particular, sterol biosynthesis. This observation led to the proposal of the possible co-evolution of the hopanoids (sterol surrogates) with ion channels in prokaryotes and the appearance of sterols with ion-channel proteins of eukaryotes (Barrantes \& Fantini, 2016).

The timing of the appearance of viruses is still a controversial issue. Some evolutionists contend that viruses originated from 'ancient' cells that existed before the last universal cellular (common) ancestor (LUCA) gave rise to modern cells, i.e. to the three superkingdoms of Archaea, 
Bacteria and Eukarya (Forterre, 2005), from ancient RNA cells that predated the LUCA (Nasir et al., 2020). In contrast, other theories support the idea that viruses evolved by recombinational reassortment of genes in a co-evolutionary process with cells rather than being ancestral to them (Hendrix et al., 2000; Adachi et al., 2020; Cui et al., 2019). A third line of thought conveys the idea that viruses stem from cells via a process of reductive evolution, as hypothesized for giant DNA viruses (Koonin \& Yutin, 2018). In the case of invertebrate viruses, co-evolution is supported by the largeeffect polymorphisms for host resistance and viral evasion, which may have been favoured by virus-mediated selection (Obbard \& Dudas, 2014).

Against this backdrop, an intriguing question is whether the cross-talk between channel-protein motifs and microenvironmental lipids observed in higher cells also occurs in viral ion-channel proteins. Indeed, the envelope lipid bilayer of influenza virus type A harbours cholesterol-rich, ordered lipid domains ('lipid rafts'; To \& Torres, 2019), the characteristic lateral heterogeneities that are employed by eukaryotic cells as signalling platforms. Moreover, the cytoplasmic tail of influenza virus $\mathrm{M} 2$ binds human annexin $\mathrm{A} 6$, a $\mathrm{Ca}^{2+} /$ lipidscaffold protein that interacts with ordered lipid domains and regulates the homeostatic equilibrium of cholesterol, while it negatively modulates viral infection (Ma et al., 2012). Similarly, a short linear motif in the cytoplasmic tail of influenza A M2 establishes interactions with another constitutive ordered lipid domain-resident protein, the cholesterol-binding protein caveolin-1; inhibition of caveolin-1 expression diminishes H1N1 influenza viral titres by hindering virus replication (Sun et al., 2010). These may represent examples of molecular mimicry, where the virus appropriates cellular elements that enable it to interact with other endogenous partners of the host cell that are normally involved in physiological mechanisms, for example, facilitating biogenesis, membrane association or trafficking of the virus, among multiple other processes.

In the case of CoVs, lipid domains have been reported to serve as entry sites for SARS-CoV in Vero E6 cells (Lu et al., 2008), possibly due to the enrichment of its receptor, ACE2, in these platforms; cholesterol depletion of ACE2-expressing cells by acute treatment with methyl- $\beta$-cyclodextrin reduced the binding of the S protein by $50 \%$ (Glende et al., 2008). The alpha- and betacoronaviruses infect only mammals (Yu et al., 2020) and may have appeared as variants of bat coronaviruses much more recently in evolutionary terms (Letko et al., 2018; Cui et al., 2019). All CoVs having orf3a structural homologs evolved from the bat gene pool, whereas all those without orf3a structural homologs derive from rodent, avian or pig gene pools (Kern et al., 2020), suggesting co-evolution of the ion-channel protein orf3a in CoVs whose reservoir is the bat.

Another interesting case is provided by the similar structure and pharmacological sensitivity of the two pentameric viral ion channels orf8a and $\mathrm{E}$ and the proton- and GABA-sensitive prokaryotic channel GLIC. The pentameric bundle formed by the first 22 residues of the 39-amino-acid-long SARS-CoV orf8a (Chen et al., 2011) provides a structural framework on which to model the homologous pentameric M2 helical array of the bacterial GLIC protein from the cyanobacterium G. violaceus (Hsu et al., 2015), a representative member of the superfamily of pGLICs (Nys et al., 2013). Both orf8a and GLIC permeate chloride ions, and the chloride flux is voltagesensitive (Hsu et al., 2015). More remarkably, the GLIC prokaryotic ion channel is blocked by memantine (Ulens et al., 2014), the same drug recently shown to inhibit the ion-channel function of the SARS-CoV-2 E protein (Singh Tomar \& Arkin, 2020). Thus, the reported lack of homology between viral and prokaryotic/eukaryotic ion channels (McClenaghan et al., 2020) may relate only to their primary sequence; their folding in space may provide the required $3 \mathrm{D}$ structure to constitute a binding site for small organic molecules acting as inhibitory drugs.

Knowledge of the phylogenetic kindredness between ionchannel proteins of human pathogenic viruses and those of animal reservoirs may contribute not only to our understanding of the biology of the virus ion channels per se, but also to the development of therapeutic strategies to combat them. There are still many open avenues that could contribute to these endeavours and thus help to prevent future pandemics. Understanding the mechanisms of coronavirus ion channels is among these opportunities.

\section{Future directions in viral ion-channel research}

During recent months, structural biology has made an unparalleled contribution to our understanding of the current pandemic. Biophysical approaches, exploiting previous methodological knowhow and information accrued over the last two decades on other CoVs, have produced new detailed data on the components of SARS-CoV-2 (Barrantes, 2021). These help to shed light on the mechanisms involved in viral recognition by host-cell receptors and possible interventions to hinder this and other steps of the infective cycle of the virus. In comparison with the massive amount of data accrued on the $\mathrm{S}$ glycoprotein, viral ion-channel proteins are still relatively unexplored from both the purely structural and mechanistic points of view. New structural data are needed to understand how viruses can alter the morphology of cellular components, modify the secretory vesicle transport system to subserve viral RNA replication, protect the spike protein from premature cleavage and efficiently assemble it into new virions through interaction with hijacked host-cell factors. A wide spectrum of techniques, in particular the powerful cryo-EM, cryotomography and super-resolution optical microscopies, offer new possibilities to investigate viral ion channels with unprecedented resolution: atomic level in the case of cryo-EM and nanometric level (the mesoscale) in the case of live specimen studies with optical nanoscopy (Barrantes, 2021).

In addition, the very nature of viral ion channels makes it inherently possible to apply a bifrontal approach combining the strengths of the structural cryo-imaging biophysical techniques (for example serial cryo-focused ion beam/scanning EM volume imaging) with single-molecule electrophysiology, in the form of single-channel patch-clamp recording of subcellular organelles, to characterize the structure-function 
correlations that are still missing in order to understand the pathogenic effects of CoVs on cellular function.

\section{Acknowledgements}

The author declares no conflicts of interest.

\section{Funding information}

Funding for this research was provided by: Consejo Nacional de Investigaciones Científicas y Técnicas (grant No. PIP 857/ 2015).

\section{References}

Adachi, S., Koma, T., Doi, N., Nomaguchi, M. \& Adachi, A. (2020). Front. Immunol. 11, 811.

Alam, I., Kamau, A. A., Kulmanov, M., Jaremko, Ł., Arold, S. T., Pain, A., Gojobori, T. \& Duarte, C. M. (2020). Front. Cell. Infect. Microbiol. 10, 405.

Almeida, J. D. \& Tyrrell, D. A. (1967). J. Gen. Virol. 1, 175-178.

Arbely, E., Khattari, Z., Brotons, G., Akkawi, M., Salditt, T. \& Arkin, I. T. (2004). J. Mol. Biol. 341, 769-779.

Barrantes, F. J. (2015). Biochim. Biophys. Acta, 1848, 1796-1805.

Barrantes, F. J. (2020). Front. Physiol. 11, 820.

Barrantes, F. J. (2021). Annu. Rev. Biophys. In the press.

Barrantes, F. J. \& Fantini, J. (2016). Prog. Lipid Res. 63, 1-13.

Behmard, E., Abdolmaleki, P. \& Taghdir, M. (2018). Biophys. Chem. 233, 47-54.

Cao, Y., Yang, R., Wang, W., Lee, I., Zhang, R., Zhang, W., Sun, J., Xu, B. \& Meng, X. (2020). Front. Mol. Biosci. 7, 565797.

Castaño-Rodriguez, C., Honrubia, J. M., Gutiérrez-Álvarez, J., DeDiego, M. L., Nieto-Torres, J. L., Jimenez-Guardeño, J. M., Regla-Nava, J. A., Fernandez-Delgado, R., Verdia-Báguena, C., Queralt-Martín, M., Kochan, G., Perlman, S., Aguilella, V. M., Sola, I. \& Enjuanes, L. (2018). mBio, 9, e02325-17.

Cavasotto, C. N. \& Di Filippo, J. I. (2021). Mol. Inform. 40, e2000115. Cavasotto, C. N., Lamas, M. S. \& Maggini, J. (2021). Eur. J. Pharmacol. 890, 173705.

Chen, C.-C., Krüger, J., Sramala, I., Hsu, H.-J., Henklein, P., Chen, Y.-M. A. \& Fischer, W. B. (2011). Biochim. Biophys. Acta, 1808, 572-579.

Chen, S.-C., Lo, S.-Y., Ma, H.-C. \& Li, H.-C. (2009). Virus Genes, 38 , 365-371.

Chien, T.-H., Chiang, Y.-L., Chen, C.-P., Henklein, P., Hänel, K., Hwang, I.-S., Willbold, D. \& Fischer, W. B. (2013). Biopolymers, 99, 628-635.

Corse, E. \& Machamer, C. E. (2000). J. Virol. 74, 4319-4326.

Cui, J., Li, F. \& Shi, Z.-L. (2019). Nat. Rev. Microbiol. 17, 181-192.

DeDiego, M. L., Nieto-Torres, J. L., Jiménez-Guardeño, J. M., Regla-

Nava, J. A., Álvarez, E., Oliveros, J. C., Zhao, J., Fett, C., Perlman, S. \& Enjuanes, L. (2011). PLoS Pathog. 7, e1002315.

Díaz, J. (2020). Front. Physiol. 11, 870.

Estola, T. (1970). Avian Dis. 14, 330-336.

Fischer, F., Stegen, C. F., Masters, P. S. \& Samsonoff, W. A. (1998). J. Virol. 72, 7885-7894.

Fischer, W. B. \& Hsu, H.-J. (2011). Biochim. Biophys. Acta, 1808, 561571.

Forterre, P. (2005). Biochimie, 87, 793-803.

Freundt, E. C., Yu, L., Goldsmith, C. S., Welsh, S., Cheng, A., Yount, B., Liu, W., Frieman, M. B., Buchholz, U. J., Screaton, G. R., Lippincott-Schwartz, J., Zaki, S. R., Xu, X.-N., Baric, R. S., Subbarao, K. \& Lenardo, M. J. (2010). J. Virol. 84, 1097-1109.

Fung, T. S. \& Liu, D. X. (2019). Annu. Rev. Microbiol. 73, 529-557.

Glende, J., Schwegmann-Wessels, C., Al-Falah, M., Pfefferle, S., Qu, X., Deng, H., Drosten, C., Naim, H. Y. \& Herrler, G. (2008). Virology, 381, 215-221.
González, J. M., Gomez-Puertas, P., Cavanagh, D., Gorbalenya, A. E. \& Enjuanes, L. (2003). Arch. Virol. 148, 2207-2235.

Guan, W.-J., Ni, Z.-Y., Hu, Y., Liang, W.-H., Ou, C.-Q., He, J.-X., Liu, L., Shan, H., Lei, C.-L., Hui, D. S. C., Du, B., Li, L.-J., Zeng, G., Yuen, K.-Y., Chen, R. C., Tang, C.-L., Wang, T., Chen, P.-Y., Xiang, J., Li, S.-Y., Wang, J.-L., Liang, Z.-J., Peng, Y.-X., Wei, L., Liu, Y., Hu, Y.-H., Peng, P., Wang, J.-M., Liu, J. Y., Chen, Z., Li, G., Zheng, Z.-J., Qiu, S.-Q., Luo, J., Ye, C.-J., Zhu, S.-Y. \& Zhong, N.-S. (2020). N. Engl. J. Med. 382, 1708-1720.

Haan, C. A. M. de, Smeets, M., Vernooij, F., Vennema, H. \& Rottier, P. J. (1999). J. Virol. 73, 7441-7452.

Harrison, S. C. (2015). Virology, 479-480, 498-507.

Hartley, J. W., Rowe, W. P., Bloom, H. H. \& Turner, H. C. (1964). Exp. Biol. Med. 115, 414-418.

Hendrix, R. W., Lawrence, J. G., Hatfull, G. F. \& Casjens, S. (2000). Trends Microbiol. 8, 504-508.

Hsu, H. J., Lin, M. H., Schindler, C. \& Fischer, W. B. (2015). Proteins, 83, 300-308.

Ke, Z., Oton, J., Qu, K., Cortese, M., Zila, V., McKeane, L., Nakane, T., Zivanov, J., Neufeldt, C. J., Cerikan, B., Lu, J. M., Peukes, J., Xiong, X., Kräusslich, H. G., Scheres, S. H. W., Bartenschlager, R. \& Briggs, J. A. G. (2020). Nature, 588, 498-502.

Kern, D. M., Sorum, B., Mali, S. S., Hoel, C. M., Sridharan, S., Remis, J. P., Toso, D. B., Kotecha, A., Bautista, D. M. \& Brohawn, S. G. (2020). bioRxiv, 2020.06.17.156554.

Koonin, E. V. \& Yutin, N. (2018). F1000Res. 7, 1840.

Lai, M. M. \& Cavanagh, D. (1997). Adv. Virus Res. 48, 1-100.

Letko, M., Miazgowicz, K., McMinn, R., Seifert, S. N., Sola, I., Enjuanes, L., Carmody, A., van Doremalen, N. \& Munster, V. (2018). Cell. Rep. 24, 1730-1737.

Li, X., Giorgi, E. E., Marichannegowda, M. H., Foley, B., Xiao, C., Kong, X.-P., Chen, Y., Gnanakaran, S., Korber, B. \& Gao, F. (2020). Sci. Adv. 6, eabb9153.

Li, Y., Surya, W., Claudine, S. \& Torres, J. (2014). J. Biol. Chem. 289, $12535-12549$.

Liao, Y., Fung, T. S., Huang, M., Fang, S. G., Zhong, Y. \& Liu, D. X. (2013). J. Virol. 87, 8124-8134.

Liao, Y., Lescar, J., Tam, J. P. \& Liu, D. X. (2004). Biochem. Biophys. Res. Commun. 325, 374-380.

Liao, Y., Tam, J. P. \& Liu, D. X. (2006). Adv. Exp. Med. Biol. 581, 199202.

Lim, K. P., Xu, H. Y. \& Liu, D. X. (2001). Adv. Exp. Med. Biol. 494, 595-602.

Lu, W., Zheng, B. J., Xu, K., Schwarz, W., Du, L., Wong, C. K., Chen, J., Duan, S., Deubel, V. \& Sun, B. (2006). Proc. Natl Acad. Sci. USA, 103, 12540-12545.

Lu, Y., Liu, D. X. \& Tam, J. P. (2008). Biochem. Biophys. Res. Commun. 369, 344-349.

Ma, H., Kien, F., Manière, M., Zhang, Y., Lagarde, N., Tse, K. S., Poon, L. L. M. \& Nal, B. (2012). J. Virol. 86, 1789-1801.

Madan, V., García, M. J., Sanz, M. A. \& Carrasco, L. (2005). FEBS Lett. 579, 3607-3612.

Maeda, J., Repass, J. F., Maeda, A. \& Makino, S. (2001). Virology, 281, 163-169.

Mandala, V. S., McKay, M. J., Shcherbakov, A. A., Dregni, A. J., Kolocouris, A. \& Hong, M. (2020). Nat. Struct. Mol. Biol. 27, 12021208.

Marquez-Miranda, V., Rojas, M., Duarte, Y., Diaz-Franulic, I., Holmgren, M., Cachau, R. \& Gonzalez-Nilo, F. D. (2020). bioRxiv, 2020.10.22.349522.

McClenaghan, C., Hanson, A., Lee, S.-J. \& Nichols, C. G. (2020). Front. Immunol. 11, 573339.

McNicholas, S., Potterton, E., Wilson, K. S. \& Noble, M. E. M. (2011). Acta Cryst. D67, 386-394.

Minakshi, R., Padhan, K., Rani, M., Khan, N., Ahmad, F. \& Jameel, S. (2009). PLoS One, 4, e8342.

Moorthy, N. S., Poongavanam, V. \& Pratheepa, V. (2014). Mini Rev. Med. Chem. 14, 819-830. 
Nasir, A., Romero-Severson, E. \& Claverie, J.-M. (2020). Trends Microbiol. 28, 959-967.

Netland, J., DeDiego, M. L., Zhao, J., Fett, C., Álvarez, E., NietoTorres, J. L., Enjuanes, L. \& Perlman, S. (2010). Virology, 399, 120128.

Neuman, B. W., Adair, B. D., Yoshioka, C., Quispe, J. D., Orca, G., Kuhn, P., Milligan, R. A., Yeager, M. \& Buchmeier, M. J. (2006). J. Virol. 80, 7918-7928.

Neuman, B. W. \& Buchmeier, M. J. (2016). Adv. Virus Res. 96, 1-27.

Neuman, B. W., Kiss, G., Kunding, A. H., Bhella, D., Baksh, M. F., Connelly, S., Droese, B., Klaus, J. P., Makino, S., Sawicki, S. G., Siddell, S. G., Stamou, D. G., Wilson, I. A., Kuhn, P. \& Buchmeier, M. J. (2011). J. Struct. Biol. 174, 11-22.

Nieto-Torres, J. L., Verdiá-Báguena, C., Jimenez-Guardeño, J. M., Regla-Nava, J. A., Castaño-Rodriguez, C., Fernandez-Delgado, R., Torres, J., Aguilella, V. M. \& Enjuanes, L. (2015). Virology, 485, 330-339.

Niu, T., Zhao, X., Jiang, J., Yan, H., Li, Y., Tang, S., Li, Y. \& Song, D. (2019). Molecules, 24, 921.

Nys, M., Kesters, D. \& Ulens, C. (2013). Biochem. Pharmacol. 86, 1042-1053.

Obbard, D. J. \& Dudas, G. (2014). Curr. Opin. Virol. 8, 73-78.

OuYang, B. \& Chou, J. J. (2014). Biochim. Biophys. Acta, 1838, 10581067.

Pervushin, K., Tan, E., Parthasarathy, K., Lin, X., Jiang, F. L., Yu, D., Vararattanavech, A., Soong, T. W., Liu, D. X. \& Torres, J. (2009). PLoS Pathog. 5, e1000511.

Pinto, L. H., Holsinger, L. J. \& Lamb, R. A. (1992). Cell, 69, 517-528.

Raamsman, M. J., Locker, J. K., de Hooge, A., de Vries, A. A., Griffiths, G., Vennema, H. \& Rottier, P. J. (2000). J. Virol. 74, 23332342.

Ren, Y., Shu, T., Wu, D., Mu, J., Wang, C., Huang, M., Han, Y., Zhang, X.-Y., Zhou, W., Qiu, Y. \& Zhou, X. (2020). Cell. Mol. Immunol. 17, 881-883.

Richardson, S., Hirsch, J. S., Narasimhan, M., Crawford, J. M., McGinn, T., Davidson, K. W., Barnaby, D. P., Becker, L. B., Chelico, J. D., Cohen, S. L., Cookingham, J., Coppa, K., Diefenbach, M. A., Dominello, A. J., Duer-Hefele, J., Falzon, L., Gitlin, J., Hajizadeh, N., Harvin, T. G., Hirschwerk, D. A., Kim, E. J., Kozel, Z. M., Marrast, L. M., Mogavero, J. N., Osorio, G. A., Qiu, M. \& Zanos, T. P. (2020). JAMA, 323, 2052-2059.

Sakai, Y., Kawaguchi, A., Nagata, K. \& Hirokawa, T. (2018). Microbiol. Immunol. 62, 34-43.

Scheller, C., Krebs, F., Minkner, R., Astner, I., Gil-Moles, M. \& Wätzig, H. (2020). Electrophoresis, 41, 1137-1151.

Schoeman, D. \& Fielding, B. C. (2019). Virol. J. 16, 69.

Shen, S., Lin, P.-S., Chao, Y.-C., Zhang, A., Yang, X., Lim, S. G., Hong, W. \& Tan, Y.-J. (2005). Biochem. Biophys. Res. Commun. 330, 286292.

Singh Tomar, P. P. \& Arkin, I. T. (2020). Biochem. Biophys. Res. Commun. 530, 10-14.

Siu, Y. L., Teoh, K. T., Lo, J., Chan, C. M., Kien, F., Escriou, N., Tsao, S. W., Nicholls, J. M., Altmeyer, R., Peiris, J. S. M., Bruzzone, R. \& Nal, B. (2008). J. Virol. 82, 11318-11330.

Snijder, E. J., Limpens, R., de Wilde, A. H., de Jong, A. W. M., Zevenhoven-Dobbe, J. C., Maier, H. J., Faas, F., Koster, A. J. \& Bárcena, M. (2020). PLoS Biol. 18, e3000715.

Stodola, J. K., Dubois, G., Le Coupanec, A., Desforges, M. \& Talbot, P. J. (2018). Virology, 515, 134-149.

Su, S., Wong, G., Shi, W., Liu, J., Lai, A. C. K., Zhou, J., Liu, W., Bi, Y. \& Gao, G. F. (2016). Trends Microbiol. 24, 490-502.

Sun, L., Hemgård, G.-V., Susanto, S. A. \& Wirth, M. (2010). Virol. J. 7, 108.

Surya, W., Li, Y. \& Torres, J. (2018). Biochim. Biophys. Acta, 1860, 1309-1317.

Surya, W., Li, Y., Verdià-Bàguena, C., Aguilella, V. M. \& Torres, J. (2015). Virus Res. 201, 61-66.
Tan, Y.-J., Teng, E., Shen, S., Tan, T. H. P., Goh, P.-Y., Fielding, B. C., Ooi, E.-E., Tan, H.-C., Lim, S. G. \& Hong, W. (2004). J. Virol. 78, 6723-6734.

Tan, Y.-J., Tham, P.-Y., Chan, D. Z. L., Chou, C.-F., Shen, S., Fielding, B. C., Tan, T. H. P., Lim, S. G. \& Hong, W. (2005). J. Virol. 79, 10083-10087.

Tasneem, A., Iyer, L. M., Jakobsson, E. \& Aravind, L. (2004). Genome Biol. 6, R4.

Teoh, K.-T., Siu, Y.-L., Chan, W.-L., Schlüter, M. A., Liu, C.-J., Peiris, J. S. M., Bruzzone, R., Margolis, B. \& Nal, B. (2010). Mol. Biol. Cell, 21, 3838-3852.

Tilocca, B., Soggiu, A., Sanguinetti, M., Babini, G., De Maio, F., Britti, D., Zecconi, A., Bonizzi, L., Urbani, A. \& Roncada, P. (2020). Microbes Infect. 22, 182-187.

To, J., Surya, W., Fung, T. S., Li, Y., Verdià-Bàguena, C., QueraltMartin, M., Aguilella, V. M., Liu, D. X. \& Torres, J. (2017). J. Virol. 91, e02158-16.

To, J., Surya, W. \& Torres, J. (2016). Adv. Protein Chem. Struct. Biol. 104, 307-355.

To, J. \& Torres, J. (2019). Cells, 8, 654.

Torres, J., Wang, J., Parthasarathy, K. \& Liu, D. X. (2005). Biophys. J. 88, 1283-1290.

Tortorici, M. A. \& Veesler, D. (2019). Adv. Virus Res. 105, 93-116.

Ulens, C., Spurny, R., Thompson, A. J., Alqazzaz, M., Debaveye, S., Han, L., Price, K., Villalgordo, J. M., Tresadern, G., Lynch, J. W. \& Lummis, S. C. (2014). Structure, 22, 1399-1407.

Unchwaniwala, N., Zhan, H., Pennington, J., Horswill, M., den Boon, J. A. \& Ahlquist, P. (2020). Proc. Natl Acad. Sci. USA, 117, 1868018691.

Venkatagopalan, P., Daskalova, S. M., Lopez, L. A., Dolezal, K. A. \& Hogue, B. G. (2015). Virology, 478, 75-85.

Verdiá-Báguena, C., Nieto-Torres, J. L., Alcaraz, A., DeDiego, M. L., Enjuanes, L. \& Aguilella, V. M. (2013). Biochim. Biophys. Acta, 1828, 2026-2031.

Verdiá-Báguena, C., Nieto-Torres, J. L., Alcaraz, A., DeDiego, M. L., Torres, J., Aguilella, V. M. \& Enjuanes, L. (2012). Virology, 432, 485-494.

Wang, K., Lu, W., Chen, J., Xie, S., Shi, H., Hsu, H., Yu, W., Xu, K., Bian, C., Fischer, W. B., Schwarz, W., Feng, L. \& Sun, B. (2012). FEBS Lett. 586, 384-391.

Westerbeck, J. W. \& Machamer, C. E. (2019). J. Virol. 93, e00015-19. Wilson, L., Gage, P. \& Ewart, G. (2006). Virology, 353, 294-306.

Wilson, L., McKinlay, C., Gage, P. \& Ewart, G. (2004). Virology, 330, 322-331.

Wolff, G., Limpens, R. W. A. L., Zevenhoven-Dobbe, J. C., Laugks, U., Zheng, S., de Jong, A. W. M., Koning, R. I., Agard, D. A., Grünewald, K., Koster, A. J., Snijder, E. J. \& Bárcena, M. (2020). Science, 369, 1395-1398.

Woo, P. C. Y., Lau, S. K. P., Lam, C. S. F., Tsang, A. K. L., Hui, S.-W., Fan, R. Y. Y., Martelli, P. \& Yuen, K.-Y. (2014). J. Virol. 88, 13181331.

Wrapp, D., Wang, N., Corbett, K. S., Goldsmith, J. A., Hsieh, C. L., Abiona, O., Graham, B. S. \& McLellan, J. S. (2020). Science, 367, 1260-1263.

Wu, Q., Zhang, Y., Lü, H., Wang, J., He, X., Liu, Y., Ye, C., Lin, W., Hu, J., Ji, J., Xu, J., Ye, J., Hu, Y., Chen, W., Li, S., Wang, J., Wang, J., Bi, S. \& Yang, H. (2003). Genomics Proteomics Bioinformatics, 1 , $131-144$.

Yan, H., Xiao, G., Zhang, J., Hu, Y., Yuan, F., Cole, D. K., Zheng, C. \& Gao, G. F. (2004). J. Med. Virol. 73, 323-331.

Ye, Y. \& Hogue, B. G. (2007). J. Virol. 81, 3597-3607.

Yu, J., Qiao, S., Guo, R. \& Wang, X. (2020). Nat. Commun. 11, 3070. Zhang, K., Hou, Q., Zhong, Z., Li, X., Chen, H., Li, W., Wen, J., Wang, L., Liu, W. \& Zhong, F. (2013). Virology, 442, 156-162.

Zhang, R., Wang, K., Lv, W., Yu, W., Xie, S., Xu, K., Schwarz, W., Xiong, S. \& Sun, B. (2014). Biochim. Biophys. Acta, 1838, 10881095. 